DOI: https://doi.org/10.47405/mjssh.v6i10.1090

\begin{tabular}{|c|c|}
\hline 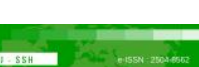 & Malaysian Journal of Social Sciences and Humanities (MJSSH) \\
\hline Malaysian Journal of & Volume 6, Issue 10, October 2021 \\
\hline (MJ-SSH) & e-ISSN : 2504-8562 \\
\hline & $\begin{array}{l}\text { Journal home page: } \\
\text { www.msocialsciences.com }\end{array}$ \\
\hline
\end{tabular}

\title{
Understanding the Link Between Inter-Group Relations and Psychological Issues
}

\author{
Jamsari Hashim¹, Romzi Ationg1, Mohd. Sohaimi Esa ${ }^{1}$ \\ 1Pusat Penataran Ilmu dan Bahasa, Universiti Malaysia Sabah (UMS) \\ Kota Kinabalu, Sabah, Malaysia
}

Correspondence: Jamsari Hashim (jamsari@ums.edu.my) \& Romzi Ationg (mrationg@ums.edu.my)

\begin{abstract}
Understanding the relationship between inter-group relations, stress and copying strategies will continue to be an integral part of modern society. However, many still tend to misunderstood about the impact of intergroup relations towards stress. Apart from that, many still lacking in understating how to deal with stress caused by inter-group relations. For this reason, explaining the significant of intergroup relations in people's stress and the way the people should deal with stress caused by inter-group relations is immensely valuable. This paper presents a discussion on the relationship between intergroup relations, stress and the way the people should deal with stress caused by inter-group relations. It is hoped that the paper provides room for improved knowledge and understanding on the relationship between inter-group relations and stress, and the way they should be dealt with stress caused by intergroup relations.
\end{abstract}

Keywords: inter-group relations, stress, copying strategy

\section{Introduction}

Understanding the inter-group relations and its relationship with people's stress and their coping strategy is a complex process, which number of studies have been conducted in this area of social psychology since sixties and seventies. As according to Singh (1991), the researchers have been especially influenced by Sherif and Sherif's (1969) series of field experiments, and by Blake, Shephard and Mouton (1964) studies and application to managerial behavior. In spite of having this rich tradition of research, the area continues to attract the attention of researchers partly because of its salience in the modern and partly because it still defies full understanding of the complex process.

This suggest that study on the link between inter-group relations, stress and copying strategies will continue to be an integral part of modern society. Despite that, however, there still misunderstanding among many on the relationship between them, as they do not really understand the concept of intergroup relations, stress and copying strategy. For this reason, and as proposed by Dovido, Gaetner, Esses and Brewer (2003), and Levy (1993), it is vital to understand the inter-group relations in this rapidly changing nature and its relationship with people's stress, and their coping strategy to make our live is much more harmony. As according to Misra, McKean, West and Russo (2000), Ahmad Fuad and Maat (2020), Ganing, Hassan and Wan Hamzah (2020), and Razak and Mydin Kutty (2021), stress is now a recognized feature of contemporary life. Every individual faces the problem of stress in varying degree of intensity sometime during their life time. Accordingly, the paper presents a discussion on the relationship between inter-group relations and stress, and the way one should deal 
with stress caused by inter-group relations. It starts with a discussion on the concept of intergroup relations. It then followed by a discussion on approaches to view inter-group relations as a source of stress, alternative approach to describe how inter-group relation made people stress, and stress and coping strategy. It ended with a brief conclusion which emphasizes the relationship between intergroup relations and stress.

\section{The Concept of Inter-Group Relations}

In general, the concept of inter-group relations refers to relations between two or more groups or between their respective members whenever individuals belonging to one group interact, collectively or individually, with another group of its members in term of their group identification (Levy, 2001; Brown, 1984; Skevington, 1980). Broadly speaking, an inter-group relation is a major factor which bringing peoples into the stress. Conflict that is create stress is a form of interaction in which people (individual or in group) perceived themselves as being continently interdependent for a struggle over some valuable resources (Gurr, 1998). In other word, in conflict, if one of the two or more realizes the goal the other(s) is left out whereas in cooperation if one realizes the goal the other realizes it too. In this context, Jha, Sinha, Gopal and Tiwary (1985) recited that conflict conceived as an interpretation processes which constitute the totally of an inter-group relation. As soon as two groups start fighting, a built-in mechanism of cooperation seems to be activated in order to prevent the conflict from getting blown out of proportion. Similarly, the events of cooperative relationship seem to contain same gains of conflict. Therefore, it is important to note that both conflict and cooperation is part of the inter-group relations process as they create people's stress. There are three approaches to views inter-group relation as a source of people's stress. This includes, conflict theory (Sherif, 1966), social identity theory (Tajfel \& Turner, 1978), and alternative approach (Singh, 1991).

\section{Approaches to View Inter-Group Relations as a Source of Stress}

Through his Conflict Theory, Sherif (1966) stated that incompatibility of goal or a negative interdependence between groups is a necessary factor for the development for inter-group conflict, which described as associated with the people's stress. A conflict of interests between groups is necessary for negative inter-group attitudes and behavior to occur. The well-known boys' camp studies (Sherif, Harvey, White, Hood \& Sherif, 1961) illustrate this study as it is considered as relevance. Sherif, Harvey, White, Hood and Sherif divided of 12 boys to 14 years of age into two distinct groups. The groups were initially encouraged to develop friendly relationship. This led to antagonism between that groups which was accompanied by hostile attitudes to each other. However, a subsequent imposition of a super ordinate goal - that is the goal which could be achieved only through cooperation between the groups - made the negative inter-group behavior disappear and led to develop positive attitudes to each other.

Blake and Mouton (1964) then, provided support for the conflict theory with adults in organizational settings. A group of executives or senior workers that is later refers as the super ordinate, had to solve problems for which supposedly, only one best solution existed. The same pattern of results, as reported by Sherif, Harvey, White, Hood and Sherif (1961), was obtained. That is, inter-group conflict occurred when the groups had incompatible goals, but inter-group cooperation developed when a series of super ordinate goals was introduced. Sherif, Harvey, White, Hood and Sherif (1961) original field experiment was partly replicated by Sussman and Weil (1960) and by Diab (1970). Tetlock (1987) found that social conflicts exist when two or more parties perceive that their current aspirations cannot be achieved simultaneously. Subsequent research under more controlled condition has largely supported these findings; groups cooperating for super ordinate goals have friendlier and less biased inter-group attitudes than those in competition (Khan \& Ryen, 1972). There are a number of findings available in the literature, which did not consider incompatible and super ordinate goals as antecedents of conflict and cooperation respectively. Tajfel (1978) for example, did not consider incompatibility of goals as the real cause of conflict. He sponsored the 'Social Identify Theory' of inter-group relations, 
which will be discussed a little. The second part of the 'Conflict Theory' is that the super ordinate goal leads to cooperation between the groups, has also been controverted in the literature.

Deschamps and Brown (1983), on the basis of an experimental study, concluded that there are circumstances when super ordinate goals may not reduce and inter-group conflict. Blake, Shepard and Mouton (1964) reported that introduction of super ordinate goals in industry did not always reduce conflict. In a chemical plant they studied the introduction of a super ordinate goal, which failed to reduce conflict between the operation and maintenance departments. More recently, Brown (1978) found that, despite the apparent common interests, the groups of engineering workers failed to cooperate and in fact showed some evidence of inter-group discrimination. A study by Skevington (1980) suggested that in certain conditions the cooperative goals might indeed increase in-group favoritism and thereby result in greater amount of conflict, which is further would made people's stress.

Tajfel (1978), the Social Identity Theory co-founder, rejected the notion that a conflict of interests is a necessary condition for the manifestation of a negative inter-group behavior that would bring peoples into the stress. Social identity theory holds that a mere division of a number of individuals into two distinct categories will generate negative inter-group attitudes and behavior. In order to explain this, Tajfel and Turner (1979) introduced of 'Social Identity' (Tajfel, 1982).

The theory postulates that individuals strive towards a positive self-identity. Part of this identity is formed by an individual's social identity. That is an individual's identity in so far as it is derived from his belongingness to one or more social groups, which he values. It is assumed that the individuals who perceive themselves as group members strive for the duals that perceive themselves as group members strive for the attainment of positive social identity. This identity is likely to be positive if a comparison with other social groups results in a positive distinctiveness of one's own category of group from another group on a valued dimension. On the contrary, if the comparison leads to a negative estimate of one's own group, several behavioral options open up for the individuals. One of them is individual mobility; individuals may leave their own group and join the comparison group. It is however, not always possible. Another option is called social creativity: group members create new dimensions for comparison from which a positive distinctiveness can be derived in favor of the comparing individuals. Or, they might change their comparison group. A third possibility suggested by Tajfel and Turner is social competition: group members engaged in a direct confrontation with initially induced a negative distinctiveness, and would strive hard to excel the initially advantaged group.

Social identity theory was primarily tested through a minimal group paradigm. In this paradigm individuals were divided into two or more groups or categories on an almost completely arbitrary basis. Then, they were to distribute money between unidentifiable members of their own and the other group(s). It appeared that in this minimal social situation to those of out-group. Even more, individuals did award differentially to the members of the out-group in an attempt to maximize the relative difference between in-group and the out-group. And, they did so, even in the situations or conditions, where this implied that their own was awarded less than the absolute maximal amount of award possible. Proponents of Social Identity Theory considered this differential allocation of money as an expression of the individual's desire to achieve a positive distinctiveness of his own group vis-à-vis out-group.

Social identity theory has stimulated a large number of studies in various settings employing most often minimal groups. Tajfel, Flament, Billing and Bundy (1971) reported that social categorization per se could be a sufficient group for in-group. Other studies using the minimal group paradigm have replicated the result (Billing, 1973; Billing \& Tajfel, 1973; Tajfel \& Billing, 1974; Turner, 1978; Wilder, 1979).

Early research on the role of categorization in inter-group behavior (i.e. Tajfel, 1978; Tajfel, Flament, Billig \& Bundy, 1971) confounded social categorization with similarity and hence Billig and Tajfel (1973) set out to examine the effects of social categorization was a sufficient condition for the establishment of inter-group discrimination. Similarity was also important but less so. This finding of 
limited importance of similarity in inter-group behavior concurs with the results of other studies (i.e. Allen \& Wilder, 1975; Deutsch, Thomas \& Garner. 1971; Dion, 1973; Sole, Merton \& Hornstein, 1975).

In face of the above-mentioned studies: there exists another set of a large number of studies, which have contradicted the social identity theory. Brainthwaite, Doyle and Lightbown (1979) have argued that the researchers using the minimal group paradigm have given a somewhat distorted picture by overemphasizing the influence of in-group favoritism and neglecting the issue of fairness. They report that norms of fairness and discrimination exert about equal influence under 'minimal' group conditions. Viewed then by them that one cannot talk about generic norm for discrimination without acknowledging a generic norm of fairness.

Rebbie and Horwitz (1969), and Rabbie and Wilkens (1971) conducted two experimental studies which suggested that social categorization by itself is insufficient to produce inter-group effects. The classis psychology experiment of Hartley (1946) also showed that out-group discrimination could occur against meaningless and an unreal out-group and that inter-group behavior may not be dependent upon any realistic inter-group discrimination. In Hartley's experiment, it was found that the subject gave stereotype out-group responses to two fictitious national categories, instead of a list of genuine categories. The experiment was replicated later on by Hall (1968). In summary, it should be noted that the two approaches summarized above are primarily concerned with the issue of the necessary and sufficient conditions for the emergence of negative inter-group behavior which will produce people's stress. They do not focus on the dynamics of inter-group conflict relations. Quite often than not, real groups are already engaged in on-going relationship of a blend of conflict and cooperation. The relevant issue in such a condition is the escalation and/or de-escalation of an already existing relationship of conflict or cooperation and the factors, which influence these processes. If this is the purpose of a research, these theories need to be supplemented by incorporating additional factors, which might explain the dynamics of relationship. Sherif did investigate the process of inter-group conflict in his field experiments (Sherif, Harvey, White, Hood \& Sherif, 1961). But the findings have restricted validity because too many uncontrolled factors were involved in the study (DeRidder, Poortinga, Scvhruijer, Tripathi, Sinha, Sinha \& Kumar, 1985).

\section{Alternative Approach to Describe How Inter-Group Relation Made People's Stress}

Recently, a third approach has been advanced which emphasizes the importance of norms and the implications of their violations for inter-group behavior (Rabbie \& Lodewijkx, 1983). This approach popularized by Singh (1991). In this approach, norms are considered to be critical because they determined invariant reactions to certain situations (Hettema, Van Heck, Appels \& Van Zon, 1984). If members of one group violate the norms of another group or the shared norms, the members of the victim group may react negatively to this norm violating behaviors (DeRidder, Poortinga, Scvhruijer, Tripathi, Sinha, Sinha \& Kumar, 1985). By the same logic, when the members of one group confirm a norm regarding social exchange, the members of an out-group are likely to feel comfortable about the actor group. Extending the logic, one may contend that the pro-social behavior of group or its members are likely to be reciprocated by cooperative behavior by the target group. The advantages of the third approach lie in its potential to explain conflict as well as cooperative relationship in an inter-group framework. This can be examining and presented as in the following discussion.

Norm Violations: A norm violation is considered as an important antecedent, which might precipitate negative inter-group behavior (DeRidder, 1983). Norm violation elicits emotional reactions and triggers an attribution process in the target group. The member would read malafide intentions of the actor group, which imply further violation of greater significance. They might even take it as a threat to the sanctity of their group. If they do not react, they might feel a loss of social identify. A number of attributions to norm violating behaviors have been reported in the literature (Duncan, 1976; Taylor \& Jaggi, 1974). The studies quoted in the literature to pro-social (norm respect) and anti-social (norm violation) behavior differ as a function of group membership of the actor. However, there are more 
than group memberships, which mediate the relationships between norm violation and subsequent retaliation or pro-social behavior and cooperative response to it.

Recently, a framework on inter-group behavior has been focuses on the interactions between members of different groups (Schruijer, DeRidder, Poortinga \& Triparthi, 1986; DeRidder, Poortinga, Scvhruijer, Tripathi, Sinha, Sinha \& Kumar, 1985). The model describes how norm violations by a particular group and its subsequent interpretation by the victim group may escalate or deescalate the inter-group conflict. For example, if there are two groups A and B, and members of group A violate the norm. Group B will try to understand whether this norm violating behavior was caused by external (e.g., situational constraints) or internal (e.g., intentional) factors. The attribution which members of Group B makes, would determine its reaction to this norm violations. Group B's reaction to this norm violating behavior by Group A will further determine the escalation or de-escalation of inter-group conflict. Group B's reaction will activate a similar attribution process in Group A. Thus, attribution process and resultant would constitute a chain of dynamic relationships between Group A and Group B. According to the model, negative inter-group behavior will escalate only if (a) Group B perceives Group A's norm behavior as norm violating, (b) Group B attributes Group A's norm violating behavior to group A's characteristics and motives and not to some environment factors, and (c) Group A perceives Group B's reaction also as norm violating. Some additional factors are also expected to influence the escalation or de-escalation of inter-group conflict. They may be the power difference between the groups, inter-group attitudes, feeling of relative deprivation and the strength of its group's members' social identity.

Summarizing the details of the model, it may be concluded that the reactions to norm violations may be sharper when the social identity of both groups is strong the victim group feels relatively deprived, and there is exists negative attitude to each other. The reactions may not be very sharp if the power differential immensely favors the actor group, and the inter-group attitude is positive. It may be worthwhile at this to make up each of the constructs involved in the model and to examine their role more carefully.

Norms: A norm is defined as a stable and shared conception of appropriate and inappropriate behavior in a given social context that dictates expectancies of others behavior and provides 'rule' for one's own behaviors (Mckiran, 1980). Norms are central to the establishment of the 'cognitive control' over the environment (Zimbrado, 1969) in that and these beliefs and expectancies function to organize experience (Sherif \& Sherif, 1969) and to make predictions about the consequences of (and thus to guide) behavior (Kelly, 1955). Thus, we can say that the norm is some social rules or standards, which prescribe appropriate, desirable, or expected conduct for all or most social groups towards all or most other groups.

Homans (1950) defined a norm as an idea in the minds of the members of a group, an idea that can be put in the form of statement specifying what the members or other men should do under given circumstances. For example, a statement of the king described is as a norm only if any departure of real behavior from the norm is followed by some punishment. Rommerveit distinguishes carefully between the individual acting as enforcer of a norm on the one hand and the individual subject to it on the other: "A social norm is a pressure existing between a norm sender's and norm reviver's behavior in a category of recurrent situations" (1954: 45).

Norms can be described as "if then" statements, in the following way (DeRidder, Poortinga, Scvhruijer, Tripathi, Sinha, Sinha \& Kumar, 1985). If a certain situation is present for a certain actor, then this actor is obliged should, ought to perform a certain behavior or abstain from a certain behavior. If an actor is behaving in a manner not in accordance with a norm, then the norm is being violated.

A variety of attributes attached to norms by DeRidder, Poortinga, Scvhruijer, Tripathi, Sinha, Sinha and Kumar (1985). There are norms do not describe behavior that they pre-or proscribe behavior, norms, at the group level, are considered as collective perceptions and not as individual ones, norms are conceived to set latitudes of acceptable or objectionable behavior, these latitudes may be different for different norms, norms pertain to certain (subsets of domains of) situations; they can vary fairly 
general to very specific, the members of a certain group must either (be able to articulate which norms exist or be aware of norm violation, or be shown to react emotionally to norm infringement), and the sanctions to norm violations range from unspecified expectations to precise rewards or punishments.

Pro-social Behavior: If a norm violation may lead to conflict between groups, normative (i.e., confirming to norms) behaviors and shows pro-social stance to another group may reciprocate by showing more cooperative behavior. Pro-social behaviors consist of those responses which have no obvious benefits for the responder but which are beneficial to the recipient (Baron \& Byrne, 1977). For example: if we provide help to someone when we obviously get benefit from the act, we are seen as behaving in our own self-interest, therefore, we don't deserve any special credit. In contrast, if we provide help when we gain nothing from it, we are seen as altruistic or pro-social and worthy of admiration.

One of the indicators of pro-social behaviors is the help given to a person or a group. Studies of reactions to help have indicated that the recipient of help subsequently returns the favor to the one who helped him (Krishnan \& Carment, 1979). This is explained on the basis of reciprocity norm (Gouldner, 1960), which prescribes that people should help and not harm their benefactors. An alternative interpretation of the finding evokes the norm of social responsibility (Berkowitz \& Daniels, 1963), which requires that an individual should help those who are dependent on him regardless of whether or not the individual has been previously helped. In short, reciprocity involves the principle of social exchange while social responsibility implies people's obligation to the needy ones.

Several experiments have been conducted to examine the combined effects of reciprocity and social responsibility. Berkowitz and Daniels (1963) found that highly dependent supervisor or senior worker in a work situation received more help than one who was said to be low on dependency. In a later study combining dependency with reciprocity, Berkowitz and Daniels (1964) found that subjects worked hardest for the supervisor or senior worker in the prior help/high dependency condition indicating the operation of both reciprocity and social responsibility norms. Gouldner (1960) has postulated the existence of a universal norm of reciprocity that makes two interrelated demands: people should help those who helped them and people should not help those have not helped them in the past. The amount of prior help has been shown by several investigators to influence the extent of help given in a particular situation (i.e. Goranson \& Berkowitz, 1966; Lanzetta \& Wilke, 1970).

Besides, in order to understand the psychological aspect as well as people's stress and their coping strategy this paper argues that term inter-group relation must refers to relation between two or more group or between their respective member, which this relation would produce conflict and cooperation. The conflict and cooperation then, would make people stressful. The stress among group member, collectively or individually occur when they were trying to strengthen their norm or in order to face the norm violation by the out-groups.

\section{People's Stress and Coping Strategy}

In this post-modern world, the incidence of stress-related problems has increased markedly over the past fifteen years (Elkind, 1984). In many cases, people's stress generally related to inter-group relations, and specifically group conflict and cooperation. The indicators of people's stress in the community specifically in the workplace as according to Compass (1992) and Youngs (1985), includes alcohol addictions, apathy, burglary, cruelty, drug addiction, excessive fooling around, gang behavior, homelessness, indifference, non-participation, promiscuity, tobacco addiction, vandalism and violence (gang fight). It taking places when the peoples were trying to prevent their norm from violated by the out-group. Consequently, inter-group relation is including both conflict and cooperation as the stress factors. As the stress is associated with the inter-group relations, it is now become vital to identify the way one usually deals with stress. Therefore, understanding stress coping strategy in brief based Lazarus' theory of coping and Tennan \& Hezberger's phenomological theory of coping is helpful. 
Lazarus' model emphasis cognitive appraisal as an intrinsic component of the coping process. The concept of appraisal is central to this theoretical formulation. An individual asks first, "what is at stake?" and second "what are the resource available to me?" (Lazarus, 1968; Folkman \& Lazarus, 1988). Lazarus' definition of coping reflects the move from a trait concept with its emphasis on dispositional variables has been found to be a poor predictor of behavior and it therefore limited (Lazarus et al, 1980). The other theory of coping is the cognitive-phenomenological theory of coping by Tennen and Hezberger (1985). This model posits that the individual and the environment are in a constant state of action and reaction. How a person does bring about impacts the environment, which in turn to impact the individual and so on. This theory is also pointed that the person-environment interaction is a constant dynamic state based on a complex set of actions and reactions.

In accordance, these theories of stress - coping are associated with a body of clinical research and practice, which on the identification of stress and stressor and the learning of skills required for the management of stressful situations. Coping strategy, therefore are including seek social support, focus on solving the problem, work hard and achieve its aims, worry about what is happening, invest in close friend/spend more time with friend, seek belong or improve relationship with others, wishful thinking, social action/joint with people who have the same concern, tension reduction/make oneself feel better by taking alcohol and so on, not cope, ignore the problem, self-blame, keep to self, seek spiritual support, focus on the positive things, seek professional help, seek relaxing diversion such as watch TV, and physical recreation.

Thus, this sub-section is set out to fill in the gaps in the current understanding between people's stress and coping strategy. As elaborated in the coping strategy above, the nucleus of this strategy is indeed a solid understanding on the important role interpersonal communication. Chandler, D., \& Munday, R. (2011) define interpersonal communication as an interaction between individuals, typically one-to-one, in either synchoronous or asynchoronous mode.

Here, the focal point of this discussion is directed to synchoronous mode because it may involve both speech and non-verbal cues. The ability to register appropriate speech pattern in terms of vocal variety, pitch and rate of voice and pronunciation and enunciation are very essential. On the other hand, nonverbal cues focuses on bodily and physical appearance. Thereby, it is suggested that sufficient knowledge on various coping strategies other than explicated in this sub-section are essential in order to lead a harmonious life.

Certainly, to answer to the question on the need to adopt many coping strategies is two-fold because each human being is created with unique DNA and hormones and environmental changes which are influential in impacting our coping mechanism.

\section{Conclusion}

This paper presents a discussion on the relationship between inter-group relations and stress, and the way one should dealt with stress caused by inter-group relations. It suggests that inter-group relations generally play important role in stress. For this reason, this paper also briefly explores the copying strategies that can be used by many in dealing with stress caused by inter-group relations. It is hoped that such move provides valuable information to the readers as a means of ensuring human being live their life happily.

\section{Acknowledgment}

We gratefully acknowledge that this paper wouldn't be produced and published without the research grant provided by the UMS. 


\section{References}

Ahmad Fuad, N.I. \& Maat, S.M. (2020). Sorotan Literatur Bersistematik: Faktor Stres dalam kalangan Guru Matematik. Malaysian Journal of Social Sciences and Humanities (MJSSH), 5(11), 167173.

Allen, V.L. \& Wilder, D.A. (1975). Categorization, Belief, Similarity and Inter-group Behavior. Journal of Personality and Social Psychology, 32, 971-977.

Baron, R.A. \& Byrne, D. (1977). Social Psychology: Understanding Human Interaction. Boston: Allyn and Bacon Inc.

Berkowitz, L. \& Daniels, L.R. (1963). Responsibility and Dependency. Journal of Abnormal and Social Psychology, 68, 275-281.

Billing, M. (1973). Normative Communication in a Minimal Inter-group Situation. European Journal of Social Psychology, 3, 339-344.

Billing, M., \& Tajfel, H. (1973). Social Categorization and Similarity in Inter-group Behavior. European Journal of Social Psychology, 3, 27-52.

Blake, R.R., Shephard, H. and Mouton, J. (1964). Managing Inter-group Conflict in Industry. Houston, TX: Gulf.

Brainthwaite, A., Doyle, S. \& Lightbown, N. (1979). The Balance between Fairness and Discrimination. European Journal of Social Psychology, 9, 149-163.

Brown, R.J. (1984). The Effect of Inter-group Similarility and Cooperative Vs. Competitive Orientation on Inter-group Discrimination. British Journal of Psychology, 23, 21-33.

Chandler, D., \& Munday, R. (2011). A dictionary of media and communication. New York: Oxford University Press

Compass, B.E. (1992). Promoting Successful Coping during Adolescent. Paper presented at the conference "Youth in the Year 2000", Marbach Castle, Germany.

DeRidder, R. (1983). Norm Violation in Dyad: The Effect of Victims, Attribution of Malevolent Intent on Reactive Aggression. Unpublished Manuscript. The Nederland: Tilburg University.

DeRidder, R., Poortinga, Y.H., Scvhruijer, S.G.L., Tripathi, R.C., Sinha, J.B.P., Sinha, D. \& Kumar, R. (1985). Psychocultural Determinants of Inter-group Relations. Nederland: Tilburg University.

Deschamps, J.C. \& Brown, R. (1983). Super ordinate Goals and Inter-group Conflict. British Journal of Social Psychology, 22, 189-195.

Deutch, M., Thomas, J.R.H. \& Garner, K.A. (1971). Social Discrimination on the Basis of Category Membership. Columbia: Teachers College, Columbia University

Diab, L.N. (1970). A Study of Inter-group and Inter-group Relations among Experimentally Produced Small Groups. Genetic Psychology Monographs, 82, 49-82.

Dion, K.L. (1973). Cohesiveness as a Determinant of Intergroup Bias. Journal of Personality and Social Psychology, 28, 163-171.

Dovido, J.E., Gaertner, S.L. \& Kawakami, K. (2003). Intergroup Contact: The Past, Present, and Future. Group Processes and Intergroup Relations, 6(1), 5-21.

Duncan, B.L. (1976). Differential Social Perception and Attribution of Inter-group Violence: Testing the Lower Limits of Stereotyping of Blacks. Journal of Personality and Social Psychology, 34, 590-598.

Elkind, D. (1984). All Grown Up and no Place to go: Teenagers in Crisis. Reading: Addison-Wesley.

Folkman, S. \& Lazarus, RS. (1988). Ways of Coping Questionnaire Test Booklet. Consulting Psychologists Press.

Ganing, C.F., Hassan, M.M. \& Wan Hamzah, W.N.N. (2020). Faktor-faktor yang Mempengaruhi Tekanan Kerja di kalangan Kakitangan Hospital Kerajaan. Malaysian Journal of Social Sciences and Humanities (MJSSH), 5(10), 151 - 177

Goranson, R.E. \& Berkowitz, L. (1966). Reciprocity and Responsibility Reduction to Prior Help. Journal of Personality and Social Psychology, 3, 227-232.

Gouldner, A. (1960). The norm of reciprocity: A preliminary statement. American Sociological Review, 25, 161-178.

Gurr, T.R. (1998). Why Men Rebel? Princeton: Princeton University Press.

Hall, R.A. (1968). The Scapegoat Theory of Prejudices. Unpublished Master Thesis, Colorado State University.

Hartley, E.L. (1946). Problems in Prejudice. New York: King's Crown Press. 
Hettema, P.J., Van Heck, G.L.M., Appels, M. \& Van Zon, I. (1984). The Assessment of the Situational Power. Paper Presented at the Second European Conference on Personality, Bielefeld, FRG.

Homans. (1950). The Human Group. In Holzer B. \& Stegbauer C. (eds) Schlüsselwerke der Netzwerkforschung. Netzwerkforschung: Springer VS, Wiesbaden.

Jha, H., Sinha, J.B.P., Gopal, S. \& Tiwary, K.M. (1985). Social Structure and Alignment: A Study of Rural Bihar. New Delhi: Usha Publisher.

Kelly, G.A. (1955). The Psychology of Personal Constructs. New York: Norton.

Krishnan, L. \& Carment, D.W. (1979). Reaction to Help Reciprocity, Responsibility and Reactance. European Journal of Social Psychology, 9, 435-439.

Lanzetta, J.T. \& Wilke, H. (1970). The Obligations to Help: The Effects of Amount of Prior Help on Subsequent Helping Behavior. Journal of Experimental Social Psychology, 6, 488-493.

Lazarus, R.S. (1968). Emotions dan Adaptation: Conceptual and Empirical Relations. In Arnold, W. J. (ed). Nebraska Symposium on Motivation. Nebraska: Lincoln, University of Nebraska, pp. 287322.

Levy, S.G. (2001). Psychology and the study of Inter-group Conflict. PEPS, 7(2), Spring.

Levy, S.G. (1993). Questions about some Fundamental Concepts and some Directions for Thinking in Study of Inter-group Conflict. Conflict Management and Pease Science, 13(1), 1-27.

McKiran, D.J. (1980). The Identification of Deviance: A Conceptualization and Initial List of a Model of Social Norms. European Journal of Social Psychology, 10, 75-93.

Misra, R., McKean, M., West, S. \& Russo, T. (2000). Academic Stress of College Students: Comparison of Student and Faculty Perceptions. College Student Journal, 34(2), 236-245.

Razak, N.A. \& Mydin Kutty, F. (2021). Daya Tahan, Strategi Daya Tindak Serta Hubungannya Terhadap Tahap Kesejahteraan Psikologi Guru. Malaysian Journal of Social Sciences and Humanities (MJSSH), 6(3), 171 - 179

Rebbie, J.M. \& Lodewijkx, H. (1983). Difference in Reactive and Instrumental Aggression between Individuals and Groups. Paper Presented at the European-Israel Conference on Group Processes and Inter-group Conflict, Israel, 14-17 October 1983.

Rebbie, J.M. \& Horwitz, M. (1969). Arousal of in-group - out-group bias by a Chance Win or Lost. Journal of Personality and Social Psychology, 13, 269-277.

Rebbie, J.M. \& Wilkens, G. (1971). Inter-group Competition and its Effects on Intra-group Relations. European Journal Social Psychology, 1, 215-234.

Rommetveit, R. (1954). Social Norms and Roles. Minneapolis: University of Minnesota Press.

Schruijer, S.G.L., DeRidder, R., Poortinga, Y.H. \& Triparthi, R.C. (1986). Norm Violations and Intergroup: A Framework for Resarach. Lisse: Swets and Zeitlenger.

Sherif, M., Harvey, O.J., White, B.J., Hood, W.R. and Sherif, C.W. (1961). Inter-group CooperationCompetition: The Robbers Cave Experiment. Norman, UK: University Book Exchange.

Sherif, M. \& Sherif, C.W. (1969). Social Psychology. New York: Harper and Row.

Sherif, M. (1966). In Common Predicaments: Social Psychology of Inter-group Conflict and Cooperation. Boston: Houngton and Miff.

Singh, R.B.P. (1991). Conflict and Cooperation: Manager-Worker Relationship. New Delhi: Anmol Publication.

Skevington, S. (1980). Inter-group Relations and Social Change within a Nursing Context. British Journal of Social and Clinical Psychology, 19, 201-212.

Sole, K., Merton, J. \& Hornstein, H.A. (1975). Opinion Similarity and Helping Behavior: Three Field Experiments Investigating the Bias of Promotive Behavior. Journal of Experimental Social Psychology, 11, 1-13.

Sussman, M.B. \& Weil, W.B. (1960). An Experimental Study of the Effects of Group Interaction upon the behavior of Diabetic Children. International Journal of Social Psychiatry, 6, 120-125.

Tajfel, H. (1982). The Social Psychology of Inter-group Relations. Annual Review of Psychology, 33, 1-39.

Tajfel, H., Flament, C., Billing, M.G. \& Bundy, R.F. (1971). Social Categorization and Inter-group Behavior. European Journal of Social Psychology, 12, 149-177.

Tajfel, H. \& Billing, M. (1974). Familiarity and Categorization in Inter-group Behavior. European Journal of Social Psychology, 1, 149-175. 
Tajfel, H. (1978). Differentiation between Social Groups: Studies in the Social Psychology of Intergroup Relations. London: Academic Press.

Tajfel, H. \& Turner, J.C. (1979). An Investigative Theory of Social Conflict. Monterrey, C. A., Books/Cole.

Taylor, D.M. \& Jaggi, V. (1974). Ethnocentrism and Causal Attributions in a South Indian Context. Journal of Cross-Cultural Psychology, 5, 162-171.

Tennen, H. \& Hezberger, S. (1985). Ways of Coping Scale. Kansas City, KS: Test Corporation of America.

Tetlock, P.E. (1987). Who gets what from whom? Contemporary Psychology, 82, 513-514.

Turner, J.C. (1978). Social Categorization and Social-discrimination. London: Academic Press.

Wilder, D.A. (1979). Reduction of Inter-group Discrimination through Individuation of the Out group. Journal of Personality and Social Psychology, 36, 1361-1374.

Youngs, B.B. (1985). Stress in Children: How to Recognize, Avoid and overcome it. New York: Arbor House.

Zimbardo, P.G. (1969). The Cognitive Control of Motivation. Glenview, Illinois: Scort-Foresman. 